\title{
Handwriting validation: results and validity of comparison materials. Case discussion
}

\author{
SORIN ALAMOREANU \\ Department of Public Law, Faculty of Law, University Babes- Bolyai \\ Cluj-Napoca, Romania \\ BOGDAN FLORESCU
}

Forensic expert

Timisoara, Romania

Obviously, such situations are followed by a new examination of the handwriting, based on the new comparison materials. Even though according to point 16 of ENFSI Code of Conduct the same expert could do the new examination, Romanian Legal Procedures are against it. It is considered that if an expert has already expressed his opinion on a certain problem, he will not be able to draw a new report on the same subject. It is our belief that this matter has to be a reviewed on its legal terms in accordance with the wider view of the ENFSI Code.

We will discuss in our presentation some cases of the upper mentioned situations and their outcome.

In most cases the notion of" handwriting validation , is synonymous to the one of "identifying the graphical author of the handwriting". Nevertheless, in some practice cases the two upper mentioned notions do not fully overlap. 
In order to reach correct results, consonant with the objective truth ${ }^{1}$, the foremost condition is that the expert is offered sufficient comparison samples (pieces). The latter will have to be sufficient both in quality and quantity, as well as really originate from the determined "X person" that is to be identified as the writer. In order to comply with these conditions, the judicial body that have ordered the writing examination have certain "proceeding tools" that allow to request from the litigating parties written documents containing undisputed samples of writing.

According to Romanian Law investigators (police officers or prosecutors) are entitled to demand, identify and gather comparison pieces.

On the other hand, during civil cases there are two distinct situations:

- during contradictory procedures, that suppose a cross debate of the evidences in court, the judge orders the litigating parties to bring forward comparison document written by the "X person". Documents submitted by one part, will be presented and discussed with the other parts that may accept them (in which case they become valid comparison pieces), or can reject them (in this case the pieces will not be used for the HWR examination).

- during uncontradictory procedures - succession debates or similar notary procedures - the comparison documents are usually submitted to the notary's attention by only one part. They will not be discussed and debated upon, thus serving as fully accepted pieces of reference for the expert.

Both in civil as well al criminal cases, the court, or other judicial body, will order writing samples to be executed by , $X$ '. This will provide full certainty for the ,paternity" of the writing samples, under the absolute presumption of authenticity.

${ }^{1}$ Handwriting validation, as essence of handwriting examination, derives from the expert's strive to identify the common or different features among suspect writing, signatures, etc. and the ones presumed to have been written by a certain known author. This assertion is generally originating in the judicial organ's indications towards the expert concerning the comparison materials (writing with a known author) that are assumed as having been created by $\mathrm{X}$ or $\mathrm{Y}$.

If this is absolutely true for the cases when handwriting samples have been created for the comparison purposes in the presence of the judicial organ, certain cases could come to the point where the presumed authors are deceased or missing, or the materials offered for judgment have been written on previous occasions (also known as "free comparison samples").

Nowa Kodyfikacja Prawa Karnego 45, 2017

(C) for this edition by CNS 
In other cases, through debate, or with the help of some other means of proof, the court will establish the origin of the samples as "created by person X". These cases are based upon a relative presumption of samples' authenticity.

If this is absolutely true for such cases when handwriting samples have been created for comparison purposes in the presence of the judicial organ, certain situations could arrive to the point where the presumed authors are deceased or missing, or the materials offered for judgment have been written on previous occasions (also known as "free comparison samples").

Generally, the designated expert will receive the comparison materials as they are, not having to undertake personal investigations in order to establish whether they originate or not from the presumed author, as they were already considered as such by the court. It is clearly stated in Art. 113 of the Criminal Procedure Codex Code that "the expert will not assume the role of a prosecution court or other control entity"2.

Even though, or should we say "because of this" some practice cases in Romanian courts have been known to come to a wrong conclusion based on counterfeit comparison materials. In good faith, the expert has expressed a conclusion of identification, validating handwritten documents. Still, the result was not the objective truth since he has been presented counterfeit materials. Erred comparison pieces have led to erred conclusions.

The upper mentioned case originated mostly as notary debated cases later legal successors went to trial contesting before the court the comparison pieces and offering for the new examination more trustworthy documents.

In most cases, the expert does not have the possibility to realise that the comparison materials are forged. Sometimes though, the writing is obviously from different writers, or the discrepancies with the general education level of the author (graphical ability, knowledge of foreign languages, level of education, etc.) and/or other qualities of the writing might "ring a bell".

We would like to illustrate the preceding ideas with some examples:

1. Transylvania's western part Banat is inhabited by mixed nationalities such as: Romanian, Hungarians, German, Serbian, that use their native languages in different documents, including last wills.

Such a testament, written in Hungarian has been submitted to the notary debate and consequently to a handwriting examination.

${ }^{2}$ Criminal Procedure Code of Romania.

Nowa Kodyfikacja Prawa Karnego 45, 2017

(C) for this edition by CNS 
When examining the comparison pieces, that were also written in Hungarian, the expert did not ask for the assistance of a certified translator, expressing a conclusion of identity.

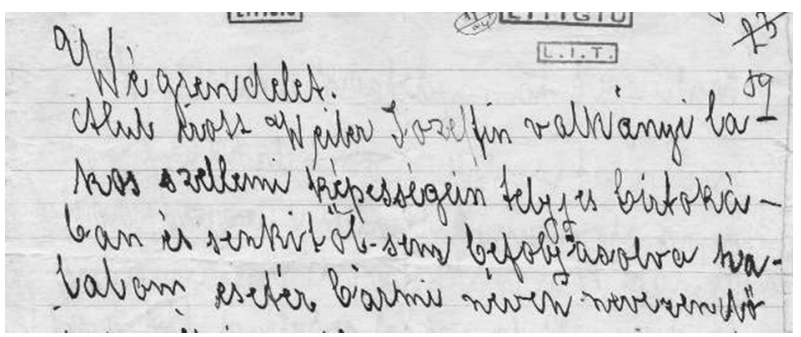

Detail of the contested testament

In fact, the conclusions were wrong since the content of the testament was littered with gross errors that were not possible at the educational level of the presumed author, but also for a native speaker of Hungarian. Such mistakes were confusions between letters with similar aspect: $\mathrm{o}-\mathrm{a}, \mathrm{j}-\mathrm{y}, \mathrm{m}-\mathrm{n}, \mathrm{h}-\mathrm{k}$.

It could be proven subsequently that the document was a fake, imitates by copying the authors writing through transparency, by a person who was not accustomed with even the basics of Hungarian.

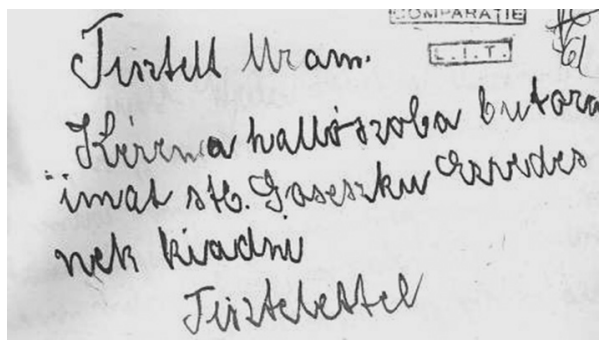

Comparison handwritings

2. A similar case involved some comparison materials allegedly originating from a former lawyer, graduated in law at Paris, thus well acquainted with French language and writing. 


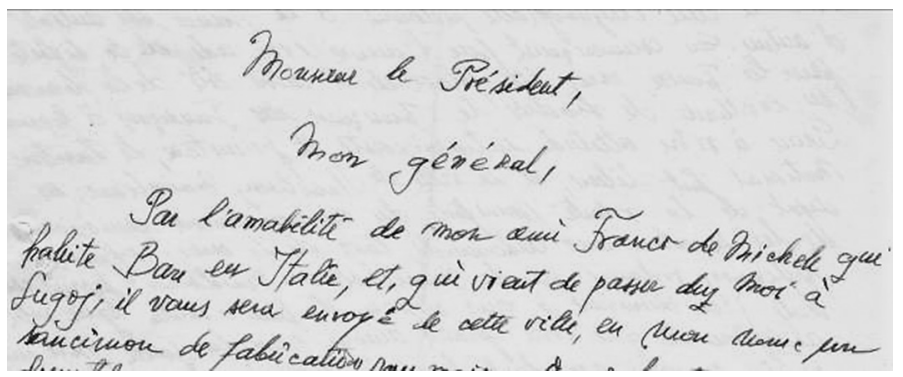

Details of a letter addressed to Gen. De Gaulle

The comparison writing was a forgery intended at eliminating the author's will as authentic.

Here are some of the spelling mistakes in the text that originate in the copying and imitation of the author's writing.

This case also might have been noticed by the first expert for the discrepancies of foreign language education level, had he known French or sought council of a certified translator.

3. In a different case, the expert could observe and demonstrate that the comparison materials did not originated from the alleged author. The differences could be easily proven since the comparison included handwriting, signatures, but also stamped models of the signature.

So, what can the expert do when confronted with similar situations?

First option would be to eliminate all suspicious pieces, (if he can prove then as forgeries), then finalize the examination on the remaining comparison materials (official papers, writing samples created in court, etc.).

Another option is to inform the judicial organs about the forgery and call for procedural actions to rectify the situation by ordering new samples. Such action is consonant to ISO CEI standards, stating that any problem concerning the beneficiary's demands will be immediately brought to his knowledge, allowing him to decide on it.

Romanian practice has two ways of dealing with such situations:

- the National Forensic Institute of the Romanian Police has working dispositions stating that the expert will not be able to comment on the 


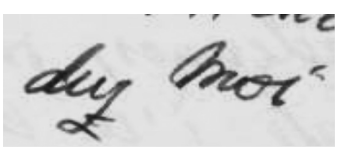

„passer du moi”

correct: ,passer chez moi"

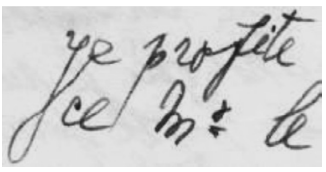

,ye profite" correct: ,je profite"

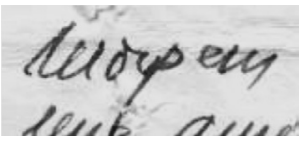

„morgen”

correct: „moyen”

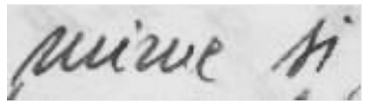

„mime si”

correct: „męme si”

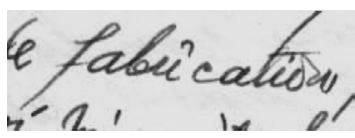

„fabricatîon"

correct: „fabrication”

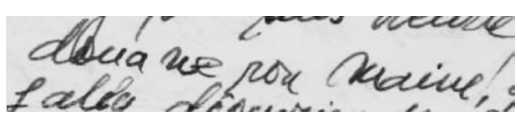

„doua ne rou maine"

correct: ,douane roumaine”

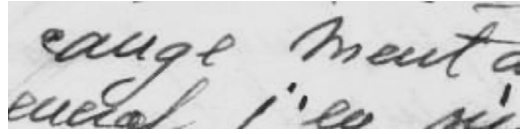

„cange ment"

correct: ,changement”

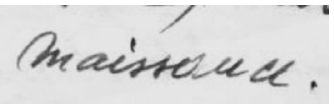

„maissance”

correct: „naissance”

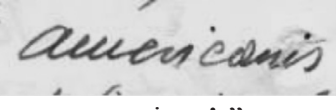

,americanis"

correct: ,americains”

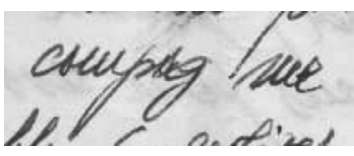

„compag me"

correct: „compagne”

comparison materials, rendering absolute the presumption of the authenticity of the comparison pieces.

- at NIFE - the Forensic Institute of the Ministry of Justice, the proceedings under the ISO 17025/2005 standards provide the expert with the possibility of demonstrating that the comparison materials have a common, or have different authors.

In an awkward situation, this contradicts the mentioned Art. 113 of the Criminal Procedure Codex Code, since the expert will have to act as a controlling authority ${ }^{3}$.

${ }^{3}$ Criminal Procedure Code of Romania, www.legislatie.just.ro. 

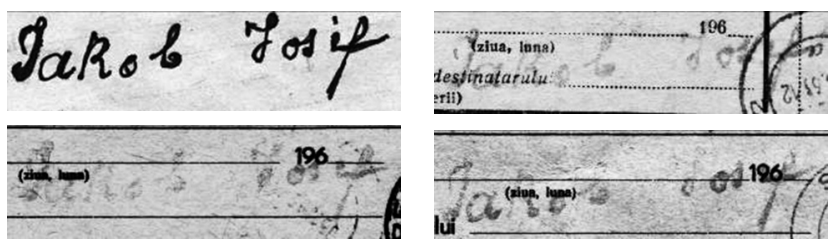

Counterfeit signatures presented as comparison pieces (stamps)
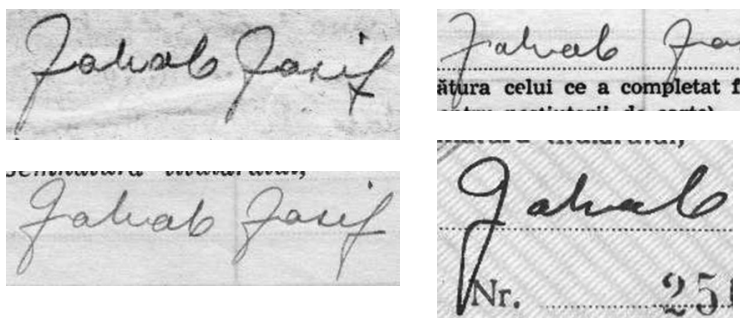

Authentic signatures of the author

We believe that, given the presumption of authenticity of the materials presented as such by the court, the expert should not prove it, but he can overturn it when confronted with forged comparison pieces (provided he can reasonably prove it).

Another problem in Romanian forensic expertise ruling is the provision prohibiting

the expert that has created a previous examination report to come back on the conclusion when "post factum" it is proven a case of false comparison pieces.

The ENFSI Code of Conduct grants the possibility (according to point 16 ENFSI Code of Conduct ${ }^{4}$ ), but Romanian legislation prohibits an expert that has formerly expressed an opinion to be part of a new expertise on the same subject - even when new comparison pieces have been presented - and they are to be solved at the next examination level (from the hierarchical point of view). It is our opinion that when con-

${ }^{4}$ Be prepared to reconsider and, if necessary, change your advice, conclusions or opinion, in the light of new information or new developments in the relevant field, and to take the initiative in informing your client and employer promptly of any such changes made. 
fronted with such situations, (counterfeit comparison pieces upturned by trustful new materials), since no error or mischief of the former expert could be retained, he may (and we think "he should") legally have a new examination. He would thus be able to review his opinion based on the new data presented to (and by) the court.

\section{Conclusions}

It is not uncommon to meet counterfeit comparison materials in certain cases of handwriting examination. Dealing with it is the true art of being an expert in handwriting examination. It is for the expert to understand and reveal (if possible) the truth about a questioned writing or signature.

He is not called upon to "guess", as he must take into consideration as originating from the alleged author the comparison pieces he has been provided with.

Validation is thus conditioned also on the skill of the judicial body or of the court to require and retain in order to be presented to the handwriting experts the right writing samples.

It is fully compliant with ENFSI Code of conduct to review one's opinion when realizing that the previous samples were false.

\section{References}

www.enfsi.eu.

ISO 17025/2005.

Criminal Procedure Code of Romania, www.legislatie.just.ro.

\section{Summary}

In most cases "handwriting validation" is synonymous to "establishing the graphical structure's author". If this is absolutely true for the cases when handwriting samples have been created for the comparison purposes in the presence of the judicial organ, certain cases could come to the point where the presumed authors are deceased or missing, or the materials offered for judgment have been written on previous occasions ( also known as "free comparison samples"). Still, practice has proven the contrary to the perfect overlapping of the two expressions. In certain debates, the contradictorily phases of evidence admission 
comparison samples offered by one of the litigating parties are supposed to the acceptance or rejection of the other part. Notary procedures though usually have no debate over the source of the comparison materials, as they generally are presented by the inheritors. Therefore, there will be no contradictorily debate upon. Romanian handwriting examination practice has met certain situations when based on the uncontested initial origin of the comparison writing, experts have validated certain writing on documents in full honesty. After a certain time legal heirs have challenged in court those documents and the identification reports based upon them, offering a wider and more trusted range of writing and signatures from the supposed author. One can assume that in such cases even though the validation was formally correct, the true author of the handwriting has not been identified and the wrong premise of handwriting paternity has led to a an erred legal appearance, being generated as such through mistaken comparison samples.

Keywords: handwriting examination, comparison materials, expert opinion, validity of comparison materials. 